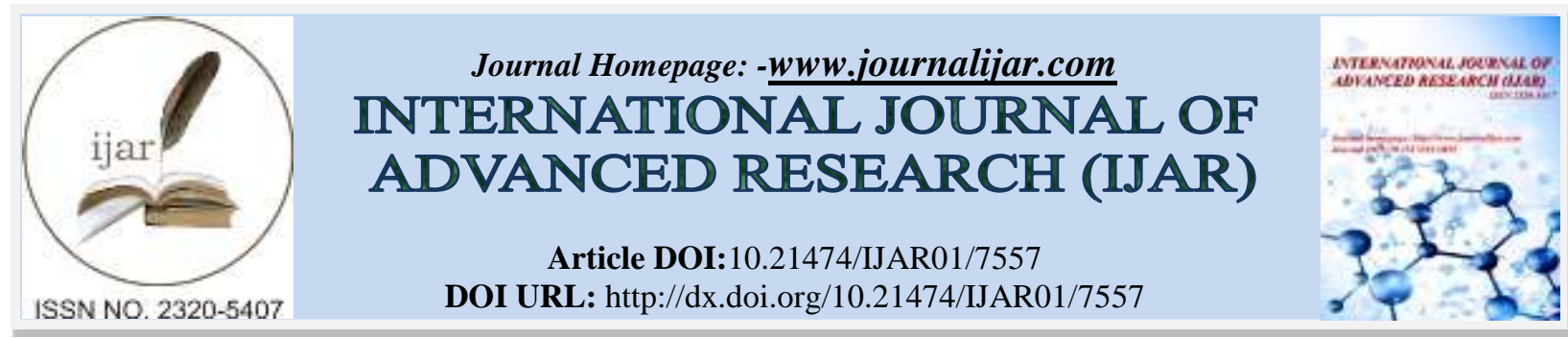

RESEARCH ARTICLE

\title{
CORRELATION BETWEEN CT SCAN AND EEG FINDINGS IN PARTIAL SEIZURES.
}

\section{Chandra Deve Varma BSK ${ }^{1}$, Balaji Bhusan Patnaik ${ }^{1}$, K Malavika $^{2}$ and Ratakonda Sruthi ${ }^{2}$.}

1. Assistant Professor, Pediatrics, Maharajah's Institute of Medical Sciences, Nellimarla.

2. Junior Resident, Pediatrics, Maharajah's Institute of Medical Sciences, Nellimarla.

\section{Manuscript Info}

Manuscript History

Received: 13 June 2018

Final Accepted: 15 July 2018

Published: August 2018

Keywords:-

Partial seizures, EEG, CT Scan Brain

\section{Abstract}

Background: Epilepsy is a chronic disorder characterized by recurrent seizures. It also has a great variety of medical and psychosocial implications. Despite the different methodologies used, most studies gave incidence rates varying from 20 to 50 per $1,00,000$. For the diagnosis of epilepsy apart from history and clinical examination other diagnostic tools like EEG and CT scan are employed.

Aim of the study: To study clinical profile and correlation of EEG and CT findings in diagnosis of partial seizures.

Study design: It is a hospital based prospective observational study.

Methods: 50 patients with partial seizures presented to Department of Pediatrics and Neonatology, MIMS, Nellimarla were studied over a period of 12 months. Correlation between abnormal CT and EEG findings were studied in different age sub groups.

Results: Out of 50 patients, $36 \%$ had both epileptiform discharges and focal lesions in CTscan brain. 4\% patients had both normal EEG and CT scan brain. $40 \%$ patients had focal lesions in CTscan brain without epileptiform discharges. $20 \%$ patients had epileptiform discharges without focal lesions in CTscan brain. EEG sensitivity in detecting focal lesions about $72.4 \%$.

Conclusion: EEG can be used as screening method in diagnosis of partial seizures and is cost effective. CT scan is mandatory to know the underlying etiology.

Copy Right, IJAR, 2018,. All rights reserved.

\section{Introduction:-}

A seizure is a paradoxical event due to abnormal, excessive, hypersynchronous discharges from an aggregate of central nervous system neurons. Epilepsy describes a condition in which a person has recurrent seizures due to chronic, underlying process. For epidemiologic purposes epilepsy is considered to be present when two or more unprovoked seizures occur in a time frame of more than 24 hours.

Incidence of epilepsy is 0.3 to $0.5 \%$ in different populations throughout world. Prevalence of epilepsy has been estimated at 5-10 persons per 1000. Despite the different methodologies used, most studies gave incidence rates varying from 20 to 50 per $1,00,000$. 
A fundamental principle is that seizures may be either partial or generalized. Partial seizures are those in which seizure activity restricted to discrete areas of cerebral cortex. Generalized seizures involve diffuse regions of brain simultaneously. Partial seizures are usually associated with structural abnormalities of brain. In contrast, generalized seizures result from cellular, biochemical or structural abnormalities. In a majority of cases, the causative factors are not evident by history and clinical examination alone. Hence diagnostic tools like EEG and CT scan brain are employed.

CT and EEG helps in structural and functional evaluation of epilepsy yielding more information than that can be provided by either method alone. As the cost of availability of CT Scan pose a problem for wide spread use, we have undertaken a study to correlate the CTscan findings with EEG to come out with a better and cost effective method of initial evaluation of patients with partial seizures.

\section{Material and methods:-}

Study design:-

It is a prospective observational study of 50 patients with partial seizures fulfilling determined inclusion criteria.

Study period:-

The study is conducted over a period of 12 months ( July 2017 to July 2018 )

Place:-

Department of Pediatrics and Neonatology, Maharaja institute of medical sciences, Nellimarla, Andhra Pradesh.

Inclusion criteria:-

1.Patients included in this study are identified by clinical observation.

2.Age is 14 and below

Exclusion Criteria:-

1. Patients on antiepileptic treatment are excluded from this study.

2.Psychological disorders mimicking partial seizures are excluded by proper clinical evaluation.

3. Other involuntary movements are excluded

\section{Methods:-}

After institutional ethical committee clearance and taking consent from the parents of patients, the study is undertaken. A predesigned proforma was used to collect the necessary data and was entered into an Excel sheat for analysis.

All 50 patients were observed and various clinical partial seizures types identified. Thorough neurological examination was done and patients with abnormal neurological findings were identified. All are subjected to EEG and CT scan brain with and without contrast. EEG was recorded by using 21 electrodes according to 10-20 international system. EEG was recorded with special measures like sleep deprivation, with sleep, hyperventilation. Single recording of EEG was noted. Correlation between abnormal CT and EEG findings were studied in different age sub groups.

\section{Observation And Results:-}

50 cases of partial seizures were included in this study, out of these $30(60 \%)$ patients were males and $20(40 \%)$ were females.

Out of 50 partial seizures $44 \%$ were simple partial seizures, $20 \%$ were complex partial seizures, $24 \%$ were simple partial with secondary generalization seizures, $8 \%$ were complex partial with secondary generalization seizures, $4 \%$ were epilepsia partialis continua 
Table 1:- Neurological examination in various partial seizure types

\begin{tabular}{|c|c|c|c|c|c|}
\hline \multirow[t]{2}{*}{ S.no } & \multirow[t]{2}{*}{ Seizure types } & \multicolumn{2}{|c|}{ Normal CNS examination } & \multicolumn{2}{|c|}{$\begin{array}{c}\text { Abnormal CNS } \\
\text { Examination }\end{array}$} \\
\hline & & $\begin{array}{c}\text { No of } \\
\text { Patients }\end{array}$ & $\begin{array}{c}\% \text { of } \\
\text { Patients }\end{array}$ & $\begin{array}{c}\text { No of } \\
\text { Patients }\end{array}$ & $\begin{array}{c}\% \text { of } \\
\text { Patients }\end{array}$ \\
\hline 1 & Simple partial seizure & 6 & 27 & 16 & 73 \\
\hline 2 & Complex partial seizures & 8 & 80 & 2 & 20 \\
\hline 3. & Simple partial with secondary & 6 & 50 & 6 & 50 \\
\hline 4. & Complex partial with secondary & 2 & 50 & 2 & 50 \\
\hline \multirow[t]{2}{*}{5.} & Epilepsia partialis continua & 2 & 100 & 0 & 0 \\
\hline & Total & & & \multicolumn{2}{|c|}{26} \\
\hline
\end{tabular}

Out of 50 cases normal neurological examination was found in 24 (48\%) patients, abnormal neurological examination was found in $26(52 \%)$ patients. Neurological examination was abnormal in $73 \%$ of patients with simple partial seizures, $20 \%$ of patients with complex partial seizures, $50 \%$ of patients with simple partial with secondary generalization seizures, $50 \%$ of patients with complex partial with secondary generalization seizures.

Table 2:- EEG results in various partial seizure types

\begin{tabular}{|c|c|c|c|c|c|}
\hline Seizure type & & \multicolumn{2}{|c|}{ Normal EEG } & \multicolumn{2}{|c|}{ Abnormal EEG } \\
\hline $\begin{array}{l}\text { No of } \\
\text { Patients }\end{array}$ & & $\begin{array}{c}\text { no of } \\
\text { Patients }\end{array}$ & $\begin{array}{c}\% \text { of } \\
\text { Patients }\end{array}$ & $\begin{array}{c}\text { No of } \\
\text { Patients }\end{array}$ & $\begin{array}{c}\% \text { of } \\
\text { Patients }\end{array}$ \\
\hline simple partial seizure & 22 & 12 & 55 & 10 & 45 \\
\hline Complex partial seizu & 10 & 2 & 20 & 8 & 80 \\
\hline $\begin{array}{r}\text { Simple partial with } \\
\text { Secondary }\end{array}$ & 12 & 6 & 50 & 6 & 50 \\
\hline $\begin{array}{c}\text { complex partial with } \\
\text { secondary }\end{array}$ & 4 & 2 & 50 & 2 & 50 \\
\hline $\begin{array}{r}\text { Epilepsia partialis } \\
\text { continua }\end{array}$ & 2 & 0 & 0 & 2 & 100 \\
\hline
\end{tabular}

Out of 22 patients with simple partial seizures, $45 \%$ had epileptiform discharges. Out of 10 patients with Complex partial seizures, $80 \%$ had epileptiform discharges. Out of 12 patients with simple partial with secondary generalization seizures $50 \%$ had epileptiform discharges. Out of 4 patients with Complex partial with secondary generalization seizures $50 \%$ had epileptiform discharges. All patients of epilepsia partialis continua had epileptiform discharges.

Graph 1:- CT scan findings in partial seizures

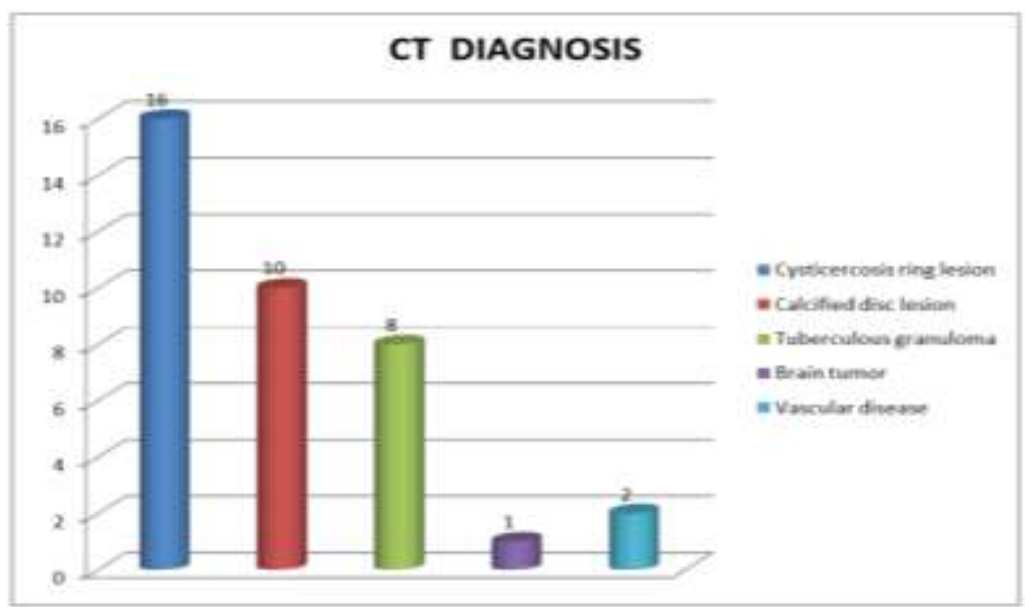


Out of 38 patients with focal lesions, $26 \%$ were calcified disc lesions, $42 \%$ were cysticercosis ring lesions, $21 \%$ were tuberculous granulomas $2.5 \%$ were brain tumors, $5 \%$ were vascular disease. Out of 50 patients $40(80 \%)$ patients started on AED 38(94\%) responded to AED but 2(6\%) patients have refractory seizures.

Table 3:- CT scan finding correlation with EEG results

\begin{tabular}{|c|c|c|c|c|c|c|}
\hline \multirow[t]{3}{*}{ S No } & \multirow{3}{*}{\multicolumn{2}{|c|}{ EEG results }} & \multicolumn{4}{|c|}{ CT scan results } \\
\hline & & & \multicolumn{2}{|c|}{ Normal CT } & \multicolumn{2}{|c|}{ Focal CT } \\
\hline & & & $\begin{array}{l}\text { No of } \\
\text { Patients }\end{array}$ & $\begin{array}{l}\% \text { of } \\
\text { patients }\end{array}$ & $\begin{array}{c}\text { No of } \\
\text { patients }\end{array}$ & $\begin{array}{c}\% \text { of } \\
\text { patients }\end{array}$ \\
\hline 1 & Normal EE & 22 & 2 & 4 & 20 & 40 \\
\hline 2 & $\begin{array}{l}\text { Epileptiforr } \\
\text { discharge }\end{array}$ & 28 & 10 & 20 & 18 & 36 \\
\hline
\end{tabular}

Out of 50 patients, 36\% had both epileptiform discharges and focal lesions in CTscan brain. 4\% patients had both normal EEG and CT scan brain. 40\% patients had focal lesions in CTscan brain without epileptiform discharges. $20 \%$ patients had epileptiform discharges without focal lesions in CTscan brain. EEG sensitivity in detecting focal lesions about $72.4 \%$.

\section{Discussion:-}

50 cases of partial seizures were studied for clinical profile and evaluated with EEG and CT scan brain. Simple partial seizures were present in $22(54 \%)$ patients, complex partial seizures in $10(20 \%)$ patients, simple partial with secondary generalization seizures in $12(24 \%)$ patients, Complex partial with secondary generalization seizures in 4 $(8 \%)$ patients, epilepsia partialis continua in $2(4 \%)$ patients.

Neurological findings were abnormal in $26(52 \%)$ patients. Brechet R. et al [1] found abnormal neurological examination findings in $65 \%$ of cases of partial seizures. Neurological examination was normal in 24 (48\%) patients.

Brechet R. et al [1] found 35\% normal neurological examination in partial seizures. CT findings were normal in 12 (24\%) patients, but the Grag and Nag [2] found normal CTscan findings in about $28 \%$ of cases in their study on partial seizures. Chopra et al [3], observed normal CTscan findings in about $22 \%$ of cases in their study on partial seizures and Daras et al [4] in 37.4\% cases. This difference could be due to determining factors like different age groups in their study. CT was found abnormal in $38(56 \%)$ patients, Daras et al [4] in 62.6\% of Cases.

The abnormalities detected were in the form of focal lesions like Calcified disc lesions (26\%), cysticercosis ring enhancing lesions in $41 \%$ of cases. Rajshekhar et al [5] found cysticercosis ring lesions in 50\% of cases, Naidoo DV et al [6] in 30\%. All single ring enhancing lesions were considered as cysticercus granuloma by Del Brutto et al [7].

Tuberculous granulomas were found in $21 \%$ patients. Rajshekar et al [5] found tuberculomas in $12 \%$ patients, but Bansal Be et al [8] found in 39.5\% of cases in their study of epilepsy. This difference could be due to the fact that all ring enhancing lesions were throught to be tuberculomas previously, because tuberculosis was considered as the commonest disease in India.

Cerebral infarcts were found in $5 \%$ patients, tumors were found in $2.5 \%$ patients. Percentage of tumors in a study by Reinkainen et al [9] is $17 \%$ and $8.8 \%$ by Haan 3 et al [10]. The percentage of focal CT lesions were almost similar in all age sub groups. Ladurner et al [11] and Mc Gahan et al [12] also showed similar findings in their study conducted at university of Graz, Austria. al in India found similar CT abnormalities in $68 \%$ of the cases with simple partial seizures.

In this study correlation was made between CTscan and clinical examination. In $92 \%$ of patients CTscan and neurological findings have shown lesion on same side that is in comparision to 55\% in a study Conducted by $\mathrm{M}$. Schumacher et al [13] at Tubingen. EEG showed normal awake patterns in 22 (44\%) patients and abnormal patterns in $28(56 \%)$ patients, Brechet $\mathrm{R}$ et al [1] in $65 \%$ of cases. There was a similar percentage of patients with normal EEG results in all age groups. Similarly the percentage of EEG showing epileptic foci did not significantly vary 
across age subgroups. When an analysis was made between the neurological findings and EEG, both abnormalities of neurological examination and epileptiform discharges were found in $28 \%$ of patients in the present study. Schumacher et al [13] have demonstrated similar features in $52 \%$ of patients.

When an analysis was made between epileptiform discharges on EEG and CT findings, the present study has shown that both focal lesions on CT and epileptiform discharges were found in 36\% of patients. $20 \%$ patients have shown epileptiform discharges alone without any abnormalities on CT scan. CT scan alone was abnormal in $40 \%$ of patients. Sorel et al [14] have shown that $38.6 \%$ of patients with partial seizures had abnormal CT findings along with epileptiform discharges on EEG. This shows EEG abnormalities can occur independently of CT scan findings in cases of partial seizures and they act complementary to each other in the evaluation of partial seizures.

\section{Conclusion:-}

Among all partial seizure types majority were simple partial seizures (54\%). Significant neurological abnormalities were present in all partial seizures types in children Among causes of partial seizures commonest were calcified disc lesions and cysticercosis ring lesions. The common causes of vascular infarcts in children are sickle cell anemia, coagulopathies and cardiac disorders.

There is Significant correlation between EEG and CT scan findings in diagnosis and lateralization of partial seizures. Single recording of EEG has a low sensitivity in detecting epileptiform discharges. EEG is a better cost effective screening method in diagnosis of partial seizures.

CT scan is mandatory in all cases of partial seizures to identify the cause of partial seizures, which is helpful in treating the underlying cause of partial seizures.

In cases of refractory seizures CT scan guides for PET/SPECT scan to plan for epileptic surgery (lesionectomy) and epileptic surgery is cost effective than life long anti-epileptics.

\section{Bibiliography:-}

1. Brechet R,Sicard C, Giovon M, Cathala HP,Bories J.Comparison of the EEG and computerized tomography findings in 500 patients hospitalized in the neurology clinic of the Salpetriere.J Neurosurg 1979 Mar; 50(3):328-32.

2. Grag and Nag : single ring enhancing lesion in CT evaluations of Epilepsy 12 (2): 94-108, 1992.

3. Chopra: Single enhancing lesion M CT evaluation of Epilepsy 2(5): 120-124,1992.

4. Daras M, Tuchman AJ, Strobos RJ: Computed tomography in adult-onset epileptic seizures in a Ocity hospital population. Clin Exp Neurol 1987;24: 159-67.

5. Raj shekar : Evaluation of single ring enhanging lesion in Epilepsy by computed tomography 6(3) : 200-224, 1993.

6. Naiduo DV, Pammenter MD, Moosa A, van Dellen JR, Cosnett JE.: Seventy black epileptics. Cysticercosis, computed tomography and electroencephalography. Epilepsia 1987 Sep-Oct: 28(5): 5 519-22.

7. Del Brutto : Single enhancing lesion in et ealuation of Epilepsy 4(2) :62-67, 1993

8. Bansal B.E., Dua A., I.K. Gupta M.S. "Appearing and disappearing C.J. Scan abnormalities in epilepsy in India an Enigma - Journal of neurology, Neuro Surgery and Psychiatry (J.Ojbb) 52 (10): 1185-7, 1989 Oct.

9. Reinikainen KJ, Keranen T, Lehtinen JM, Kalvilainen R, Saari T, Riekkinen PI: CT brain scan and EEG in the diagnosis of adult onset seizures. EEGEMG Z Elektroenzenphalogr Elektromyogr Verwandte Geb 1976 Dec; 7(4): 189-.

10. Haan J, Deppe A.: Complex focal seizures; studies based on the cranialcomputer tomogram, clinical aspects and longitudinal EEG studies. S Afr Med J 1987 Dec 19; 72(12): 837-8.

11. G. Ladurner, and W.D. Sager (1979): Summary:The value of CT and EEG in the diagnosis of epilepsy. Fotschr. Neurol.Psychiat, 47: 264-268.

12. McGahan, IP., Dublin, A.B. and Hill, R.P. (1979): The evalution of seizure disorders by computerized tomography. J. Neurosurg. 50, 328-332.

13. M. Schumacher, F. Schumm and H.D. Langohr: Correlative EEG and CT findings in epilepsies of early and late onset. Neurology Clinic. Tubingen. 12(6): 624-36.

14. Sorel L, Rucquoy-Ponsar M, Harmant J.: Electroencephalogram and CAT scan in 393 cases of epilepsy. Electroencephalogr Clin Neurophysiol 1991 Aug; 79(2): 108-13. 